\title{
Mild Intellectual Disability at the Postsecondary Level: Results of a Survey of Disability Service Offices
}

\author{
Allyson G. Harrison \\ Queen's University \\ Alana Holmes \\ Cambrian College
}

\begin{abstract}
Disability Service Staff at colleges and universities in Ontario, Canada were surveyed regarding the number of students arriving at their offices with the label of mild intellectual disability. Information was obtained regarding criteria used in association with this label, documentation required to support the classification, and accommodations provided, as well as the types of programs in which these students enroll and their success in those programs. Results demonstrate little consistency across institutions regarding the criteria employed when making this identification, and the accommodations and supports provided. Even with supports and accommodations, respondents estimated that fewer than $25 \%$ of such students are able to succeed at the postsecondary level, although a larger percentage appear to benefit from specialized college programs. Best practice guidelines are needed with respect to assessment and diagnosis of this condition, and specialized programs may be required to address success and retention at the postsecondary level.
\end{abstract}

In North America we are experiencing an increase in the demand for disability-related accommodations and supports at the postsecondary level (Brinkerhoff, Shaw, \& McGuire, 1993; Canadian Association of Disability Service Providers in Postsecondary Education, 1999; Henderson, 1995; Ministry of Training, Colleges and Universities: Postsecondary Education Division, 2008; Vogel, Leyser, Wyland, \& Brulle, 1999). Disability Services Offices (DSOs) across Canada are charged with the task of arranging appropriate accommodations and supports for students with diagnosed disabilities. The accommodations and supports provided to such students are not meant to ensure academic success (Lovett, Gordon, \& Lewandowski, 2009); rather, they are meant to allow otherwise qualified students the opportunity to participate and demonstrate their knowledge unencumbered by the effects of their specific disability. In other words, accommodations provide "access not success" (Lovett et al., 2009, p. 94). Academic accommo- 
dations are also meant to be reasonable, and are determined based on both the nature of the specific functional impairments caused by the disability and also the educational or testing environment in which the individual will be functioning. As such, there must be some rationale to explain how any proposed accommodation or support will negate or minimize the impact of the impairment on the task in question (Lovett et al., 2009).

One of the issues facing DSOs across Canada in general, and Ontario in particular, is how one determines who qualifies as a person with a disability and whether it is based solely on an identification label provided to him/her by the elementary or secondary school he/she attended. This is particularly true of a group of students in Ontario who have been given the identification of having a "mild intellectual disability" (MID; Ontario Ministry of Education, 2001). The overall purpose of this paper is to provide results of a survey of heads of DSOs at Ontario colleges and universities regarding the accommodations they provide for students with MID and the success rate of these students in their settings.

MID is not a recognized diagnosis; it is not currently found in any diagnostic codebook or manual, and is not employed as an educational category in any other Canadian province but Ontario. It is a term that was adopted by the Ministry of Education in Ontario to help them identify and provide service to a group of students who were struggling to meet the academic requirements of the regular classroom. Even though it is not a recognized diagnosis, because the Ministry of Education may create categories of "Exceptionality Identification" (Ontario Ministry of Education, 2001), this term has been used to describe a sizable number of students in the educational system, all of whom have received varying degrees of assistance and program modifications to allow them to graduate from high school. This includes substantial course modifications (not simply accommodations) or course substitutions. Many of these students are now applying to postsecondary programs in Canada and are expecting that they will receive accommodations, supports, and course modifications similar to those provided to them in high school.

The distinction between accommodations and modifications is neither small nor insignificant, yet its influence is often neglected or misunderstood when evaluating the success and capabilities of students with MID. Accommodations are supports and services that allow otherwise qualified students with special education needs to participate equally in an educational setting by minimizing or eliminating artificial barriers to academic involvement (Education Quality and Accountability Office, 2009). Students who receive academic accommodations must still meet the same academic standards as their peers, but the manner in which they demonstrate this may differ. Modifications, on the other hand, involve changes to course content, assessment, and to performance criteria (Education Quality and Accountability Office, 2009). If students labeled as MID were typically provided with modifications to the educational curricula during elementary and secondary school, then the question becomes whether they are, in fact, "otherwise qualified" to attend postsecondary educational institutions. Modifications are simply not offered within the regular postsecondary setting, and thus students for whom course content was previously modified may not have acquired fundamental skills required for academic success at the postsecondary level. The ramifications for success and retention rates of such students entering the postsecondary system of education is clear; if this body of learners was deemed in need of intensive support and modifications to the curriculum of high school in order to succeed, then how likely is it that they will progress through community college or university without such aids in place? Clearly, Ontario's postsecondary institutions would benefit from better understanding the progress and experience of students with MID within their programs. 


\section{How are MID and Other Related Disorders Defined?}

One of the essential requirements for providing accommodations to persons with disabilities is a clear definition of the disorder in question (Dumont, Willis, Janetti, \& Farr, 2000). At present, there is no consensus in Ontario regarding who qualifies for a label of MID, nor how it is to be defined. Different jurisdictions and stakeholders employ differing criteria for identifying individuals in this group, and there seems to be little consensus as to how such students are to be identified (Harrison \& Holmes, 2009; Harrison \& Troister, 2010).

Intellectual Disability is a term that refers to the same population of individuals who were previously diagnosed with Mental Retardation. The American Association on Intellectual and Developmental Disabilities (2013; formerly known as the American Association of Mental Retardation) defined intellectual disability as follows: "Intellectual disability is a disability characterized by significant limitations both in intellectual functioning and in adaptive behavior as expressed in conceptual, social, and practical adaptive skills. This disability originates before the age of 18." Their definition goes on to specify that those with an Intellectual Disability have IQ scores that fall below 70 or 75 (i.e., below the 2 nd percentile, but accounting for measurement error it could be up to the 5th percentile), which is considered a limitation in intellectual functioning. In the Ontario $\mathrm{K}-12$ school system, students who would qualify as having such an Intellectual Disability are classified as having a Developmental Disability. The Ontario Ministry of Education (2001) defined Developmental Disability as:

A severe learning disorder characterized by (a) an inability to profit from a special education program for students with mild intellectual disabilities because of slow intellectual development; (b) an ability to profit from a special education program that is designed to accommodate slow intellectual development; and (c) a limited potential for academic learning, independent social adjustment, and economic self-support. (p. A20)

In contrast, the Ontario Ministry of Education (2001) defined MID as:

A learning disorder characterized by (a) an ability to profit educationally within a regular class with the aid of considerable curriculum modifications and supportive services; (b) an inability to profit educationally within a regular class because of slow intellectual development; and (c) a potential for academic learning, independent social adjustment, and economic self-support. (p. A20)

Neither description provides any operationally defined criteria or directions to school boards as to how to determine whether a student fits this disability profile. Individual school boards are therefore left to their own devices regarding how they will actualize these definitions when identifying students within their board. This has created much confusion within the province. For instance, a review of practices across Ontario district school boards revealed a great deal of inconsistency in identifying MID (Harrison \& Troister, 2010). Only 10\% of Ontario school boards employ a combination of IQ score, impairments in adaptive functioning, and academic impairment as suggested by the Ministry's definition when identifying students as having MID. Similarly, about one third employ both IQ scores and impairments in adaptive functioning and approximately $43 \%$ of boards employ only an IQ score when making this identification. The review (Harrison \& Troister, 2010) also found no agreement on the IQ range required for diagnosis. IQ score criteria ranged from below the 1st percentile to below the 17 th percentile, with the majority of school boards employing IQ scores below either the 2nd percentile or between the 2 nd to 8 th percentile. Thus, students in Ontario who are being labeled as MID could vary widely in their intellectual abilities. Accounting for measurement error, IQ scores could range 
from 50-90, and students so labeled could have drastically different levels of academic and adaptive functioning, depending on the criteria used for identification within their district.

Additionally, independent of any data from the Ministry of Education in Ontario, members of the College Committee on Disability Issues (2008) decided that students with MID "have Intelligence Test results (IQ's) between 70-79 (2nd to 9th percentile)" (p.1), and that they may also be described as having Borderline Intellectual Functioning (BIF) or being a slow learner (Lacéne, 2008).

The Diagnostic and Statistical Manual of Mental Disorders-IV Text Revision (DSM-IVTR; American Psychiatric Association, 2000) does include BIF, but it is listed as a "V" code on Axis II, which means that it is not a recognized clinical disorder. Furthermore, the DSM-IV-TR specifically states that "V-codes represent conditions that are the focus of clinical attention but are not considered disorders" (American Psychiatric Association, 2000, p. 5). By comparison, other V codes in the DSM-IV-TR include Occupational problems, Academic problems, Relational problems, Parent-Child relational problems, Phase of life problems, Bereavement, Religious or spiritual problems, and Malingering. Hence, BIF is not a disorder or diagnosis, but rather a condition that may potentially impact manifestation and treatment of other disorders. Within the V codes, DSM-IV-TR defined BIF as follows: "This category can be used when the focus of clinical attention is associated with borderline intellectual functioning, that is, an IQ in the 71-84 range" (American Psychiatric Association, 2000, p. 740) and is coded on Axis II (Shaw, Grimes, \& Bulman, 2005). In other words, it is not coded as a disability.

In the United States, there is no special education category for children who fall within the BIF description (Mercer, Jordan, Allsopp, \& Mercer, 1996; Morris et al., 1998; Shaw, 2008), and so they are not eligible for special education services. However, with the No Child Left Behind initiative (2002) it is suggested that any early school problems demonstrated by such children would be identified through the Response to Intervention model (Lau et al., 2006).

It is therefore quite apparent that no agreement exists regarding how to determine who qualifies for the label of MID, or whether MID or BIF qualify as a disability diagnosis, although it seems clear that use of IQ scores alone appears to be the method of identification used most frequently by Ontario school boards (Harrison \& Troister, 2010). This is worrisome, as IQ scores in and of themselves have some inherent variability due to scoring and clinician errors as well as intra-individual factors that can affect obtained scores on any given day (see Kuentzel, Hetterscheidt, \& Barnett, 2011, and Ryan \& Schankenberg-Ott, 2003, for an in depth discussion of the effects of administration and scoring errors on obtained IQ test scores). Indeed, in recognition of the imprecise nature of IQ scores, the diagnosis of Mental Retardation (now referred to as Intellectual Disability) was modified in 1959 (Heber as cited in Sheerenberger, 1983) to require not only an IQ score at or below 70 (plus or minus 5 IQ points to account for measurement error), but also evidence of substantial impairment in adaptive functioning, and evidence that the impairments have been chronic and present since before the age of 18 (American Association on Mental Retardation, 1992; Grossman, 1983; Luckasson et al., 2002).

\section{Current State of Affairs in the Postsecondary Sector}

It is the case that some postsecondary institutions have begun offering modified participation programs for students with intellectual disabilities so that they may participate in an ageappropriate setting (see Neubert, Moon, Grigal, \& Redd, 2001, and Hart, Grigal, Sax, Martinez , \& Will, 2006, for descriptions of such programs). Community Integration through Cooperative Education (CICE) programs offered at some postsecondary institutions are examples of such 
postsecondary options in Ontario. The CICE programs provide individuals with intellectual disabilities and other significant learning challenges the opportunity to experience college life, pursue a postsecondary education, and develop skills which will help prepare them for employment. However, the content of the programs is modified and the students do not graduate with a college diploma, but may instead receive a certificate.

The issue at present is that students labeled as having MID are not necessarily enrolling in CICE programs but instead enrolling in mainstream postsecondary programs, and expect that they will be provided with academic accommodations and course modifications similar to those offered to them in high school. Ontario's community colleges, and likely its universities, have been unprepared for this group of learners entering into their institutions. This is well reflected in the results of a survey conducted by the College Committee on Disability Issues (2008), which concluded that all colleges struggled with how to support and accommodate students arriving in mainstream programs with the label of MID. The same survey also concluded that "all colleges are calling MID a disability; and colleges are providing accommodations" (College Committee on Disability Issues, 2008, p.1).

At present, no formal information exists regarding the number of students labeled MID enrolled in Ontario's postsecondary sector, nor do we know how best to assist such students once they enter college or university. Unlike provision of academic adjustments to students with other disabilities, it is unclear what accommodations would be appropriate for students so labeled, as accommodations are meant to minimize impact of a specific impairment, allowing an otherwise qualified student the opportunity to demonstrate acquired knowledge and skill. In the case of students with MID, a specific physical, sensory, or processing impairment is not known to be the root of the expressed academic challenges. Impairment is typically more general and more extensive than a series of individual specific impairments. This lack of a specific processing deficit and absence of notable peaks or strengths in the learning profile produces consternation over what might be an appropriate accommodation or set of accommodations at the postsecondary level. Accommodations are intended to "level the playing field" for individuals with disabilities, to enable individuals to complete tasks with autonomy, and typically, not providing advantage to everyone else but removing a disadvantage for individuals in question. For example, students who are legally blind but otherwise qualified to enter postsecondary education have impaired vision as the sensory deficit at the root of their learning challenges. Providing accommodations that will allow these individuals to navigate campus and access textbook material, lecture notes, and exams enables them to complete the task of learning independently. Thus, the accommodation of Braille exams assists the student who is legally blind while it would not advantage a student with intact vision. The question that remains is how to remove the disadvantage for students who may not be able to acquire the required level of skill and knowledge necessary for course mastery, and may not have attained the standard educational requirements for courses in which they were enrolled due to curricular modifications during high school.

In order to determine what policies and supports should be put in place for such students, it is first necessary to gain a general understanding regarding how postsecondary institutions define this group, what documentation they require regarding disability, the types of programs these students choose, the typical supports used, whether course content is modified, and the success rate for students with MID at the postsecondary level. This survey was undertaken to investigate these questions. It is assumed that appropriate policies and services can be developed only after service providers have a better understanding of the nature of the issues faced by such students, and when an agreed-upon way to identify these students is determined. 


\section{Method}

\section{Participants and Data Collection Procedures}

A survey link (Survey Monkey) was e-mailed to all heads of DSOs in Ontario in the fall of 2008. Participants were informed that this was an anonymous survey being conducted by a government-funded assessment centre and that participation was entirely voluntary. One follow-up e-mail was sent to each institution requesting participation. Of the 44 publicly funded institutions in Ontario, 24 are 2-year colleges and 20 are 4-year universities (Ontario Ministry of Training, Colleges and Universities, 2010).

Each institution was asked to ensure that only one individual responded to the survey, preferably the head of their Disability Services Office. In total, 34 institutions replied to the survey: 24 out of $24(100 \%)$ were from the college sector and 10 out of $20(50 \%)$ were from universities. Half of the 24 colleges run CICE programs, programs designed to give students with intellectual disabilities the opportunity to participate in college-adapted programs and activities. Responses from one university were not used because the respondent reported that the survey was answered based on individuals with learning disabilities rather than those with MID.

\section{Measure}

A 20-item questionnaire was developed to survey current practices and number of students served at each institution, and to gain information about the objectives outlined for this survey (see Appendix). Topics queried included demographics, estimates of the proportion of students with special needs with a MID label, the types of documentation provided by students with MID, how the institution defines MID, the accommodations provided to students with MID, an estimate of the program(s) chosen by these students, and an estimate of their success rate. Response types included choosing from a set of options or open-ended questions. We were particularly interested in knowing the extent to which both colleges and universities are dealing with students identified as MID, whether there was a consensus about method of identification, programs of study, and accommodations provided, and degree of success in meeting course requirements.

Frequency data were analysed using chi square (or Fischer's Exact test if assumptions of the chi square could not be met) to assess significant differences between colleges and universities and between schools providing the CICE program and those that do not have the program. Many respondents did not answer every question; therefore, the number of respondents is reported with each finding.

\section{Results}

\section{Demographics of Participating Institutions}

Institutions of all sizes were represented in the survey (see Table 1), yet two-thirds of respondents were from urban areas mostly in central Ontario. The number of students with disabilities served by respondents ranged from estimates of less than $500(21.2 \%)$ to more than 2000 (3.0\%); however, the majority of institutions estimated that they served fewer than 1000 $(63.6 \%)$ per year.

The estimated number of students with MID enrolled in postsecondary institutions. Respondents were asked to estimate both the number of students with MID and the percentage of the student population with disabilities that the reported number represented. There 
Table 1

Regional Representation of Participants as a Function of Size of Institution

\begin{tabular}{|c|c|c|c|c|c|c|c|c|c|c|}
\hline \multirow[b]{3}{*}{ School Area } & \multicolumn{8}{|c|}{ Region of Ontario } & & \\
\hline & \multicolumn{2}{|c|}{ North } & \multicolumn{2}{|c|}{ Southwestern } & \multicolumn{2}{|c|}{ Central } & \multicolumn{2}{|c|}{ Eastern } & \multicolumn{2}{|c|}{ Total } \\
\hline & $n$ & $\%$ & $n$ & $\%$ & $n$ & $\%$ & $n$ & $\%$ & $n$ & $\%$ \\
\hline Urban & 2 & 9.5 & 6 & 28.6 & 11 & 52.3 & 2 & 9.5 & 21 & 63.6 \\
\hline Non-urban & 4 & 33.3 & 1 & 8.3 & 3 & 25.0 & 4 & 33.3 & 12 & 36.4 \\
\hline Total & 6 & 18.1 & 7 & 21.2 & 14 & 42.4 & 6 & 18.1 & 33 & 100.0 \\
\hline
\end{tabular}

Note. Urban area $=$ population $>200,000$

was clearly a much higher incidence rate of students with MID within the colleges, where the estimated numbers ranged from 0-100 students with MID per year. A majority of responding universities reported servicing fewer than 6 students with MID per year; only one reported having 20-25 such students on their case list and this school also reported a student population over 20,000 . All universities and $74 \%$ of colleges reported that $10 \%$ or fewer of their student population with disabilities were classified as having MID. Of the remaining colleges, all but one reported this to be $11-20 \%$. One college reported that over $90 \%$ of their students with disabilities were identified with MID. It is noteworthy that this college also provided the CICE program.

\section{Documentation Criteria}

As shown in Table 2, the majority of schools (59.4\%) used an IQ level in the range of 7080 as the criteria for MID. Seven institutions did not respond to this question. Both colleges and universities reported receiving psychoeducational reports, Identification, Placement and Review Committee reports, and Individual Education Plans as documentation of MID. Two trends are evident with respect to the documentation and its contents (see Figure 1). While colleges received more documentation stating a "diagnosis" of MID than did universities (70\% vs. 33\%), this difference was not significant, Fischer's Exact test significance $=.20, n=31$. Second, the criteria colleges use to document MID is significantly less rigorous than that used by universities. Colleges utilized IQ scores alone $79 \%$ of the time whereas universities used this sole criterion $33 \%$ of the time, Fischer's Exact test significance $=.059, n=25$.

A great deal of variability existed in the terminology reportedly used to identify these students. Indeed, as shown in Figure 2, while the majority of institutions noted that a "diagnosis" of MID had been made in the assessment report provided, many commented that a "diagnosis" of BIF was made, or even more worrisome, the diagnosis was given as Learning Disability-Not Otherwise Specified (LD-NOS). In addition, Individual Education Plans described students with this exceptionality as being below average, of limited intellectual ability, or a slow learner.

Table 2

IQ Requirement for the MID Designation as a Function of Institution

\begin{tabular}{|c|c|c|c|c|c|c|c|c|c|}
\hline \multirow{3}{*}{$\begin{array}{l}\text { Institution } \\
\text { College }\end{array}$} & \multicolumn{7}{|c|}{ IQ Criteria } & & \\
\hline & \multicolumn{2}{|c|}{ No criterion reported } & \multicolumn{2}{|c|}{$<70$} & \multicolumn{2}{|c|}{$70-80^{a}$} & \multirow{2}{*}{$\frac{80-90}{n}$} & \multicolumn{2}{|c|}{ Total } \\
\hline & $n$ & $\%$ & $n$ & $\%$ & $n$ & $\%$ & & $n$ & $\%$ \\
\hline CICE & 1 & 9.0 & 3 & 27.3 & 7 & 63.6 & 0 & 11 & 34.4 \\
\hline no CICE & 1 & 8.3 & 1 & 8.3 & 10 & 83.3 & 0 & 12 & 37.5 \\
\hline University & 4 & 44.4 & 3 & 33.3 & 2 & 22.2 & 0 & 9 & 28.1 \\
\hline Total & 6 & 18.7 & 7 & 21.9 & 19 & 59.4 & 0 & 32 & 100.0 \\
\hline
\end{tabular}




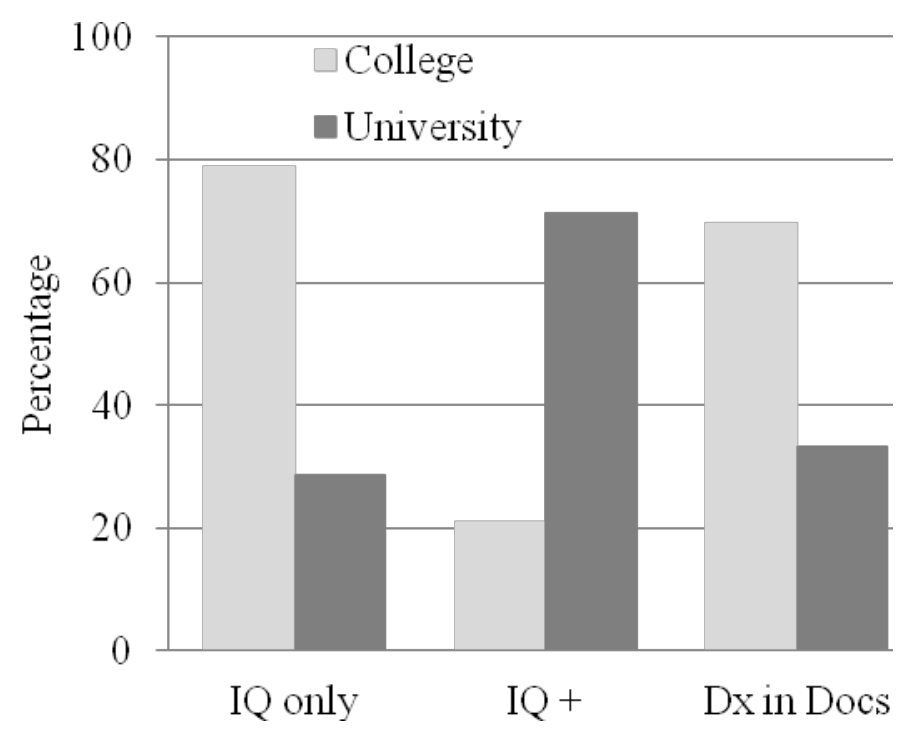

Figure 1. Percentage of institutions that allow for possible criteria in the diagnosis of MID. Note: Dx in Docs = Documentation includes a statement of diagnosis.

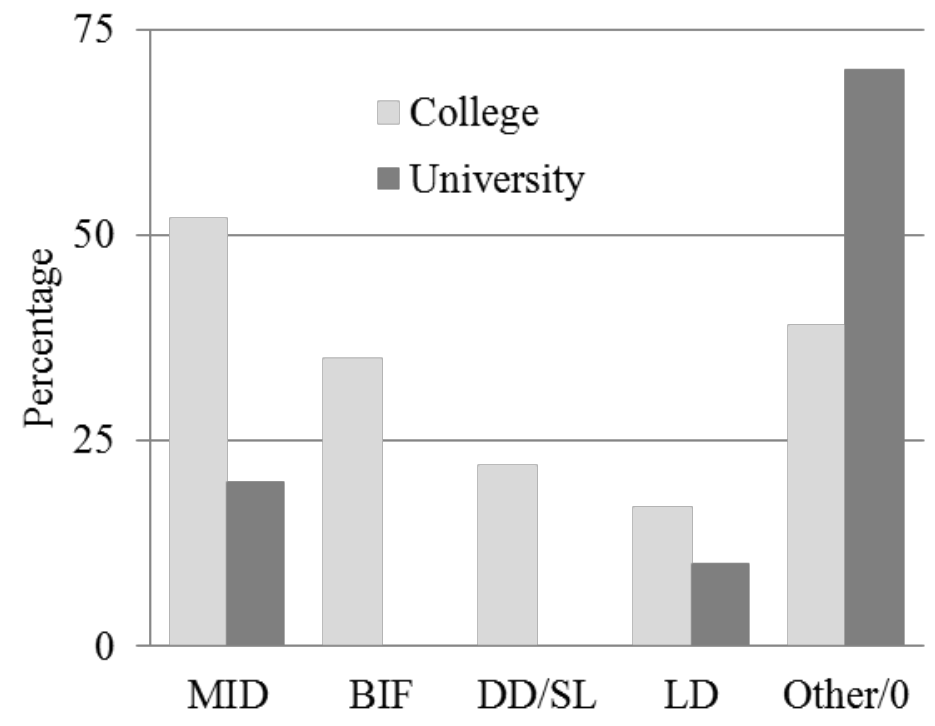

Figure 2. Percentage of institutions using various labels for MID in their diagnosis. Note that more than one label could be reported by a school. MID = Minimal intellectual disability, BIF $=$ Borderline intellectual function, DD/SL $=$ Developmental disability/slow learner, $L D=$ Learning disability, Other $/ 0=$ Other label or no label reported.

\section{Services and Supports Provided to Students with MID}

Modifications. No university and only one college (4.2\%) that responded provided modifications of course or admission requirements. Of note, this college provided both modifications for courses and for admission requirements as part of their CICE program, which itself is a modified educational program. 
Accommodations. Universities and colleges reported providing a variety of accommodations to students with documentation of MID (see Table 3). Furthermore, the extent to which colleges and universities provided mainstream campus study skills/supports, a "no cost" accommodation (i.e., no extra cost as the service is funded for all students), to students with MID is not markedly different at $83 \%$ vs. $70 \%$. However, similarities in provision of services wane thereafter with the remaining accommodations offered much more frequently by colleges than universities. Perhaps the greatest disparity occurs in the clarification of exam questions, tutoring, and the provision of approval to use Bursary for Students With Disabilities (BSWD) ${ }^{1}$ funds for coaching or learning strategies; colleges offer these more than twice as often as do universities.

\section{Success Rate}

Respondents were asked to provide their best estimate of the percentage of students with MID who, having received services through their office, graduated from their program of study. The majority of respondents $(85 \%)$ believed from their experience that fewer than half of students with MID graduate from postsecondary education (see Table 4). Qualitative comments from respondents were also quite revealing (see Table 5). A consistent theme in these comments is that students labeled as MID are often unable to complete the demands of their program and that those who do require a great deal of support along the way.

Table 3

Percentage of Institutions Providing Accommodation by Type of Accommodation

\begin{tabular}{|c|c|c|c|c|}
\hline \multirow[b]{2}{*}{ Accommodations Provided } & \multicolumn{3}{|c|}{ Percentage of Institutions } & \multirow[b]{2}{*}{$x^{2}$ sig. } \\
\hline & Universities & $\begin{array}{c}\text { Colleges } \\
\text { with CICE }\end{array}$ & $\begin{array}{l}\text { Colleges } \\
\text { no CICE }\end{array}$ & \\
\hline Mainstream campus study skills/supports & 70 & 91 & 75 & \\
\hline Tutoring: learning strategist & 50 & 55 & 83 & \\
\hline tutoring & 40 & 91 & 92 & ** \\
\hline tutoring $>3$ hours/week/course & 10 & 46 & 25 & \\
\hline Assistive technology & 60 & 82 & 83 & \\
\hline BSWD for technology & 40 & 73 & 75 & \\
\hline Proofreading & 20 & 18 & 42 & \\
\hline EA in class or lab & 0 & 18 & 0 & \\
\hline Exams: extra time & 60 & 100 & 100 & ** \\
\hline separate space on exams & 40 & 46 & 50 & \\
\hline scribe/reader for exams & 10 & 55 & 58 & * \\
\hline tutor for clarification at exams & 0 & 9 & 58 & ** \\
\hline Part time: course load & 50 & 64 & 100 & * \\
\hline approval for OSAP & 40 & 73 & 83 & \\
\hline Approval of BSWD for assessment update & 50 & 91 & 92 & * \\
\hline Alternate format & 30 & 27 & 67 & \\
\hline
\end{tabular}

\footnotetext{
${ }^{1}$ The Ontario Government administers a federal grant (on behalf of Canada Student Loans) and provincial grant, the BSWD. The BSWD is a bursary made available to both full- and part-time Ontario students with either permanent or temporary disabilities who have disability-related educational costs for services or equipment that are not covered by another agency or service and are required for postsecondary participation. Students with disabilities can obtain up to $\$ 2,000$ per academic year through this provincial bursary. Approval for use of these funds must be obtained from the Disability Services Office at the postsecondary institution that the student attends.
} 
Table 4

Estimated Percentage of Students with MID who Successfully Complete a Postsecondary Program as a Function of Institution

\begin{tabular}{lccccc}
\hline & \multicolumn{5}{c}{ Percentage estimate of students with MID completing postsecondary } \\
Institution & $<10$ & $10-25$ & $26-50$ & $51-75$ & $>75$ \\
\hline College & 30 & 40 & 0 & 10 & 20 \\
with CICE & 11 & 33 & 33 & 22 & 0 \\
no CICE & 88 & 0 & 0 & 12 & 0 \\
University & & & &
\end{tabular}

\section{Discussion}

The present survey was conducted to help determine the number of students coming to postsecondary institutions with an identification of MID and to obtain information about how this group of students is being identified, accommodated, and to what extent they are succeeding.

Data collected in this survey indicate that students with a label of MID represent less than $10 \%$ of students (between 5-7\%) being served by disability offices in Ontario postsecondary institutions, with the majority attending community colleges (approximately $78 \%$ of all students with MID) as opposed to universities. Although this may not seem like a sizeable number, to put it in context, students with visual impairments represent $1.39 \%$, while students with hearing impairments represent $2.95 \%$ and students with physical disabilities represent $7.54 \%$ of the students served by college disability offices (College Committee on Disability Issues, 2007-2008 data collection). The implications for retention are therefore substantial. If $10 \%$ of students serviced by disability offices at postsecondary schools have a classification of MID but have a low chance of graduating from their program, then courses better suited to these types of learners and supports beneficial to them stand a good chance of improving the postsecondary experience of this group. In these times of fiscal restraint and competition for enrolment, this is an area where colleges in particular stand to benefit (given that the majority of students with this label choose college over university) if they find ways to cultivate and support students with MID.

Definitions being used at the postsecondary level are more consistent than in the elementary and secondary panels (c.f., Harrison \& Troister, 2010); however, unlike the school boards who typically view these students as being similar to those with mild intellectual disabilities, the majority of colleges view them as having intellectual abilities up to the 9th percentile. Further, not all schools are employing the same criteria for identification of this group of students, and for the most part colleges only use IQ scores for this designation. Reliance on IQ scores alone for

Table 5

\section{Comments from Respondents}

- Students with MID who succeed: are generally highly motivated, have realistic goals, good organization and study skills, seek assistance and support, and take a reduced course load.

- Although students with MID often ask for course modifications, these are almost always refused.

- A significant increase in students with MID has been observed.

- Often they complete after a prolonged period and with much support from our office. Sometimes I wonder who actually passed the program-us or them.

- Difficulties due to over-accommodating/modifying in high school. Very hard transition to postsecondary. Sometimes receive Grade 12 college English credit, but aren't working at the level.

- Complete program when in less demanding academic areas and commit to additional time.

- We have only had 2 students over the last 10 years to my knowledge, both only lasted one semester and then dropped out. 
classifying any group as having a disability is a practice that has been rejected for over 50 years, and so it is worrisome that this practice persists at the postsecondary level.

Another trend identified in this survey is that the labels MID and BIF are appearing in psychoeducational reports linked to diagnosis — as opposed to identification — and an accompanying list of recommendations for academic accommodations and supports. It is difficult to resist the notion that students are reportedly being given a diagnosis of MID or BIF as a way to classify/obtain disability status. Overall, just under a third of the universities report receiving documentation that provided a diagnosis, while almost three quarters of the colleges say documentation provided a diagnosis. Given that no DSM-IV-TR MID diagnosis exists, it is difficult to understand this finding. While some clinicians appear to employ the "diagnosis" of LD-NOS, this too is worrisome as this diagnostic category is typically reserved for those who demonstrate some learning difficulties but who fail to meet the specific criteria for any other LD diagnosis.

Survey data suggest that universities and colleges also provide similar types of accommodation, but colleges do so to a greater extent. Both sectors also approve BSWD funds and partial course loads for this group, and again colleges do so more frequently. Universities take a more conservative approach to the documentation of MID, requiring supplementary information regarding functional implications in addition to IQ scores to determine MID, and universities offer fewer accommodations and supports. These differences are not just due to the differences in numbers of respondents or students with MID, since all results are compared in terms of percentages of institutions responding. Of note is the fact that the BSWD monies are meant to fund disability-related supports and services for otherwise qualified students with permanent disabilities, and yet it is still not clear that those labeled as MID (as identified by the Ministry of Education) have completed the academic requirements at the same level as their peers (hence otherwise qualified) or if they would qualify as someone with a permanent disability. Given that the BSWD in particular is a limited funding program, excessive use of these funds for students who may not qualify as disabled may threaten to deplete already limited resources for other students with bona fide disability needs.

The survey also shows that the majority of respondents estimated that one quarter or fewer of students labeled as MID are successful in postsecondary school despite heavy use of existing supports, along with tutoring and accommodation services. Even with the supports provided, both the data and anecdotal comments from respondents suggest that the chance for failure appears to be heightened for this group of students. Yet, what of the $25 \%$ or so who are successful in their bid for postsecondary credentials? Perhaps they represent the groups of students identified by the high school system who had IQ scores at or below the 17th percentile who, given the standard error of measurement, might in fact have IQ scores that actually fall within the average range. Alternatively, these may be students whose actual diagnosis should have been a learning disability rather than MID, in that their overall IQ score may have been subject to the "mark penalty" (Dumont \& Willis, 2001a, 2001b), due to the lowering effect that their impaired working memory and/or processing speed impairments had when calculating overall IQ. With accommodations for these underlying impairments, such students were then able to accurately demonstrate their capabilities. Certainly, such a finding highlights the need to better understand who are the students that succeed, to determine what factors help predict such success.

\section{Limitations}

This study provides preliminary data regarding the postsecondary functioning of students labeled as having MID in Ontario and thus may not be generalized to a larger jurisdiction. While 
most community colleges participated in this survey, one major limitation is the lack of information regarding the enrolment or supports required for such students at the university level. Given the small number of such students reportedly registering with university DSOs, however, this finding may reflect an actual trend whereby hardly any students with MID are successfully applying to universities in Ontario. Nevertheless, more information from universities is needed to make definitive statements about the number of such students currently utilizing the services provided by DSOs.

A second limitation is that this survey relied exclusively on self-report data. While there is no reason to believe that the DSOs provided inaccurate data, it may be that their subjective opinions regarding numbers served, or the number of reports that actually used the term "diagnosis," may be inaccurate. Future studies should seek to obtain more objective information wherever possible.

Finally, we did not specifically ask how many of the students with MID were enrolled in CICE, as opposed to mainstream, college programs. It is possible that some college DSOs reported on students enrolled in such programs; however, at the time of this survey CICE programs were very new and only one college indicated that they had modified admission requirements for students seeking admission to their school. As such, we do not believe that the majority of students identified as MID in this survey were participating in CICE programs but have no way to determine exact numbers. Further research into participation rates of students with MID in regular versus CICE programs is therefore needed.

\section{Implications}

The results of this survey have implications for future research, for policy decisions, and for DSOs and postsecondary personnel.

Implications for further research. A study of the characteristics of students with MID who go on to succeed at the postsecondary level in comparison to those who do not is needed as this may shed light on the factors that best predict long-term academic success. Also needed is a study to examine the homogeneity of students currently given this label to determine whether results from any research studies can be generalized to students identified as having MID.

Implications for policy. The results of this survey, along with the findings regarding the lack of consistency across Ontario school boards with respect to classification criteria, speaks to the need for the development of an operationalized definition of the group of traits currently being labeled MID. Ideally, such a condition would be identified not simply with IQ scores, but would also include evaluation of impairments in both academic and adaptive functioning so as to ensure that students who are otherwise average are not being inadvertently labeled as impaired.

At present, it is unclear whether or not individuals identified as having MID actually qualify as persons with disabilities, and may depend on how this label was determined (Harrison \& Troister, 2010). This has implications for funding policies at the postsecondary level in that students with this label appear to need much support and may require financial assistance, and yet often do not succeed despite this intensive support. It seems clear that there is no consistency either within colleges or between colleges and universities regarding whether and to what extent provincial funding for students with disabilities (i.e., BSWD) may legitimately be employed to support these students or which types of supports or services can be offered currently to assist them in their academic careers. Finally, best practice guidelines are also needed with respect to 
assessment and diagnosis of this condition, including an emphasis on the need for good background documentation prior to making this identification.

Implications for postsecondary institutions. It seems clear that students who have received modified academic programs at the high school level are choosing to enter postsecondary education and yet may not be able to participate equally due to intellectual limitations. In line with research regarding postsecondary programs for students with intellectual disabilities (e.g., Neubert \& Moon, 2006; Neubert et al., 2001), continued development of specialized CICE programs at the postsecondary level may allow for such students to participate meaningfully in postsecondary education, and the results from this survey suggest that they may have a better chance of succeeding if enrolled in such a specialized program. Postsecondary institutions may need to investigate how they could deliver such programs to attract and retain a broader range of students, so as to allow students with lower intellectual potential the ability to participate in a postsecondary environment while also increasing their skills and knowledge base.

\section{References}

The American Association on Intellectual and Developmental Disabilities. (2013). Definition of Intellectual Disabilities. Retrieved from http://www.aaidd.org/content_100.cfm?navID=21

American Association on Mental Retardation. (1992). Mental retardation: Definition, classification, and systems of supports. Washington, DC: Author.

American Psychiatric Association. (2000). Diagnostic and statistical manual of mental disorders (DSM-IVTR; 4th ed.). Washington, DC: Author.

Brinkerhoff, L., Shaw, S., \& McGuire, J. (1993). Promoting postsecondary education for students with learning disabilities: A Handbook for practitioners. Austin, TX: Pro-Ed.

Canadian Association of Disability Service Providers in Postsecondary Education. (1999). Towards developing professional standards for students with disabilities in postsecondary education in Canada. Ottawa, ON: Author.

College Committee on Disability Issues. (2008, February 7). Provincial meeting of the college committee on disability issues. Retrieved from http://www.disabilityissues.ca/minutes.html

Dumont, R., \& Willis, J. (2001a). Using the DWI or GIA. Retrieved from http://alpha.fdu.edu/psychology /using_the_dwi_or_gia.htm

Dumont, R., \& Willis, J. (2001b). Use of the Tellegen and Briggs formula to determine the Dumont-Willis indexes (DWI-1 and DWI-2) for the WISC-IV. Retrieved from http://alpha.fdu.edu/psychology /WISCIV_DWI.htm

Dumont, R. P., Willis, J. O., Janetti, J., \& Farr, L. P. (2000). Process for identifying a specific learning disability. In J. O. Willis \& R. P. Dumont (Eds.), Guide to the identification of learning disabilities (2nd ed.). Peterborough, NH: Author.

Education Quality and Accountability Office. (2009). Guide for accommodations, special provisions, deferrals and exemptions support for students with special education needs and english language learners. Retrieved from http://www.eqao.com/pdf_e/09/Sacg_Xe_0409_web.pdf

Grossman, H. J. (Ed.). (1983). Manual on terminology in mental retardation. (1983 Rev.). Washington, DC: American Association on Mental Deficiency.

Harrison, A.G., \& Holmes, A. (2009, May). Mild Intellectual Disability: Research and best practices. College Council on Disability Issues Annual Meeting, Huntsville, ON. Retrieved from https://www.google.ca $/$ search?q=Mild+Intellectual+Disability\%3A+Research+and+Best+Practices\&rlz=1C1LDJZ_enCA501 CA505\&aq=f\&oq=Mild+Intellectual+Disability\%3A+Research+and+Best+Practices\&aqs $=$ chrome .0 .57 $.2069 \mathrm{j} 0 \&$ sourceid $=$ chrome \&ie $=\mathrm{UTF}-8$

Harrison, A. G., \& Troister, T. (2010). Survey of Ontario Boards of Education regarding diagnostic criteria employed for identification of MID. Unpublished manuscript. 
Hart, D., Grigal, M., Sax, C., Martinez, D., \& Will, M. (2006). Postsecondary education options for students with intellectual disabilties. Research to Practice, 45. Retrieved from http://www.communityinclusion .org/article.php?article_id=178

Henderson, K. (1995). College freshmen with disabilities: A triennial statistical profile. Washington, DC: American Council on Education and HEATH resource center.

Kuentzel, J. G., Hetterscheidt, L. A., \& Barnett, D. (2011). Testing intelligently includes doublechecking Wechsler IQ scores. Journal of Psychoeducational Assessment, 29, 39-46. doi:10.1177 /0734282910362048

Lacéne, K. (2008, November). Mild intellectual disability. Proceedings of the Mobile Assessment Team Conference, Alliston, $\mathrm{ON}$.

Lau, M. Y., Sieler, J. D., Muyskens, P., Canter, A., Vankeuren, B., \& Marston, D. (2006). Perspectives on the use of the problem-solving model from the viewpoint of a school psychologist, administrator, and teacher from a large Midwest urban school district. Psychology in the Schools, 43, 117-127. doi:10 $.1002 /$ pits. 20135

Lovett, B., Gordon, M., \& Lewandowski, L. (2009). Measuring impairment in a legal context: Practical considerations in the evaluation of psychiatric and learning disabilities. In S. Goldstein \& J. Naglieri (Eds.), Assessing impairment: From theory to practice. New York, NY: Springer.

Luckasson, R., Borthwick-Duffy, S., Buntinx, W., Coulter, D.,Craig, E., \& Reeve, A.,...Tassé, M. J. (2002). Mental retardation: Definition, classification, and systems of supports (10th ed.). Washington, DC: American Association on Mental Retardation.

Mercer, C. D., Jordan, L., Allsopp, D. H., \& Mercer, A. R. (1996). Learning disabilities definitions and criteria used by state education departments. Learning Disability Quarterly, 19, 217-232. Retrieved from http://ldq.sagepub.com/

Ministry of Training, Colleges and Universities: Postsecondary Education Division. (2008). Disabilities statistics at Ontario universities for discussion at IDIA [PowerPoint slides presented at the IDIA meeting, Nov. 3, 2008].

Morris, R. D., Stuebing, K. K., Fletcher, J. M., Shaywitz, S. E., Lyon, G. R., Shankweiler, D. P.,...Shaywitz, B. A. (1998). Subtypes of reading disability: Variability around a phonological core. Journal of Educational Psychology, 90(3), 347-373. doi:10.1037//0022-0663.90.3.347

Neubert, D. A., \& Moon, M. S. (2006). Postsecondary settings and transition services for students with intellectual disabilities: Models and research. Focus on Exceptional Children, 39(4), 1-9. Available from http://www.lovepublishing.com/catalog/focus_on_exceptional_children_31.html

Neubert, D. A., Moon, M. S., Grigal, M., \& Redd, V. (2001). Post-secondary educational practices for individuals with mental retardation and other significant disabilities: A review of the literature. Journal of Vocational Rehabilitation, 16(3-4), 155-168. Retrieved from http://www.iospress.nl/journal/journal-ofvocational-rehabilitation/

No Child Left Behind (NCLB) Act of 2001, Pub. L. No. 107-110, § 115, Stat. 1425 (2002).

Ontario Ministry of Education. (2001). Special education: A guide for educators. Retrieved from http://www .edu.gov.on.ca/eng/general/elemsec/speced/guide.html

Ontario Ministry of Training, Colleges and Universities. (2010, September 23). Employment Ontario. Retrieved from http://www.ontario.ca/education-and-training/go-college-or-university-ontario

Ryan, J., \& Schankenberg-Ott, S. (2003). Scoring reliability on the Wechsler Adult Intelligence Scale-third edition (WAIS-III). Assessment, 10, 151-159. doi:10.1177/1073191103010002006

Shaw, S. (2008). An educational programming framework for a subset of students with diverse learning needs: Borderline intellectual functioning. Intervention in School and Clinic, 43(5), 291-299. doi:10.1177 $/ 1053451208314735$

Shaw, S., Grimes, D., \& Bulman, J. (2005). Educating slow learners: Are charter schools the last, best hope for their educational success? The Charter Schools Resource Journal, 1, 10-20. Retrieved from http://www .cmich.edu/academics/educ_humanservices/units/EHSTCSRJ/Pages/default.aspx

Sheerenberger, R. C. (1983). A history of mental retardation. Baltimore, MA: Brookes Publishing.

Vogel, S. A., Leyser, Y., Wyland, S., \& Brulle, A. R. (1999). Students with learning disabilities in higher education: Faculty attitudes and practices. Learning Disabilities Research and Practice, 14, 173-186. doi:10.1207/sldrp1403_5 


\section{Authors' Note}

Correspondence concerning this article should be addressed to Allyson G. Harrison, Clinical Director, Regional Assessment and Resource Centre, Queen's University, Mackintosh-Corry Hall, B100, 68 University Avenue, Kingston, ON, Canada, K7L 3N6.

Email: harrisna@queensu.ca

Funding for this research was provided by the Ministry of Training, Colleges and Universities of Ontario. The opinions as expressed in this paper are those of the authors and do not necessarily reflect those of the funder. We also wish to thank Dr. Irene Armstrong for her assistance in creating the tables and graphs in this manuscript, and for her editing support. 
Survey Questions

\section{Appendix}

1. Do you work in a college or university?

- College

- University

2. Does your institution have a Community Integration through Cooperative Education (CICE) program, or similar program for students with intellectual disabilities who require a modified curriculum?

- Yes

- No

3. How many students attend your institution?

- $0-5,000$

- $5,000-10,000$

- $10,000-15,000$

- $15,000-20,000$

- Over 20,000

4. In what region of Ontario is your institution?

- Northern Ontario

- Southwestern Ontario

- Central Ontario

- Eastern Ontario

5. Do you consider your campus to be primarily urban (in a city over 200,000 ) or less urban (in a city of $<200,000$ )?

- Primarily urban (city of $>200,000$ )

- Less urban (city of $<200,000$ )

6 . How many students with disabilities does your office serve each year?

- $0-500$

- $500-1,000$

- $1,000-1,500$

- $1,500-2,000$

- Over 2,000

7. Although you may not track this group specifically, given your best estimate, how many students with mild intellectual disability (MID) does your disability office serve?

8. As above, given your best estimate, what percentage of students registered with your disability office would be considered to have mild intellectual disability (MID) (These might be part of your LD category)?

- $0-10 \%$

- $11-20 \%$

- $21-30 \%$

- $31-40 \%$

- $41-50 \%$

- $51-60 \%$

- $61-70 \%$

- $71-80 \%$

- $81-90 \%$

- $91-100 \%$

9. Please describe the types of documentation you received from practitioners and/or secondary schools that indicate MID. (Check all that apply).

- Psychoeducational report

- Psychological report

- IEP

- Doctor's note

- Other, please specify

10. Does this documentation typically provide a diagnosis?

- Yes

- No 
11. If yes, what diagnosis is actually made?

12. In your disability office, what level of overall intellectual functioning is considered to fit with a designation of MID? (Check all that apply.)

- IQ below 70

- $\quad$ IQ between 70-80

- IQ between 80-90

- Other, please specify

13. Do you require any other proof of impairment other than IQ scores (e.g., similar to diagnosing mental retardation, do you require additional proof apart from an IQ score to confirm that the student has difficulty functioning in more than one major life area?)

- Yes

- No

14. Please indicate what supports or accommodations your office provides to students with MID, if any. (Check all that apply.)

- Referral to mainstream campus study skills support resources

- Referral to Learning Strategist (ESF)

- Access to assistive technology on campus

- Access to BSWD for assistive technology

- Extra time on exams

- Separate room for exams

- Reader/scribe for exams

- Tutoring

- Tutoring more than 3 hours/week/course

- Educational assistant in class/lab

- Proofreading/editing

- Clarification of exam questions by tutor

- Modifications of academic course requirements

- Modifications of admissions requirements

- Part-time course load

- Approval of $40 \%$ load for OSAP purposes

- BSWD for assessment or updated assessment

- Alternate format materials

15. For which of the following costs would you use the Bursary for Students With Disabilities? (Check all that apply.)

- Psycho-educational assessment or re-assessment

- Content tutoring (no disability-related adaptation required)

- Specialised tutoring (using alternate format, AT, or disability-specific strategies)

- Assistive technology purchase

- Educational assistant (in-class support)

- Coaching

- Learning strategist

- Photocopy costs

- None

- Other, please specify

16. Would you support a $40 \%$ course load as an accommodation of disability in a memo to OSAP?

- Yes

- No

- Comment 
17. How many students with MID request accommodation in the form of modified requirements, such as reduced academic expectations (volume or style of work) exemption from expectations, modified content level of work?

- None

- $1-2$ student/year

- 5-10 students/year

- More than 10 students/year

18. What type of program do your students with MID most often select? (Check all that apply.)

- Applied Arts

- Arts

- Applied Business

- Business (B. Comm)

- Applied Engineering/Technology

- Engineering

- Health Sciences

- Science

- Skilled Trades

- Community Integration Through Cooperative Education (CICE)

- Other, please specify

19. Approximately what percent of the MID students at your institution successfully complete their chosen course of study?

- $<10 \%$

- $10-25 \%$

- $26-50 \%$

- $51-75 \%$

- $>75 \%$

20. Is there anything else you would like to add?

Thank you for participating in this survey. We hope the results will be informative for you and will help identify how we can best help students. 